\title{
Universidade: espaço privilegiado para a formação de professores de Educação Física
}

Paulo Roberto Veloso Ventura Universidade Estadual de Goiás

\section{Resumo}

O presente artigo reúne acúmulos deste autor na primeira década do século XXI, tempo dedicado especialmente aos estudos sobre a formação profissional em Educação Física. Aborda o processo de entrada na universidade e a relação dos atores desta instituição com o processo de formação profissional. Na prática pedagógica inerente a esta relação, tece considerações sobre as indissociabilidades que permeiam o processo do ensinar e aprender e questiona o trato com o conhecimento que ocorre nos cursos de graduação e as consequências que esta realidade provoca nos espaços de intervenção profissional da área. Defende a formação única e generalista, pela licenciatura ampliada, com centralidade na formação humana.

Palavras-chave: Universidade. Formação profissional. Educação física. Licenciatura ampliada. 


\section{The university: a privileged space for the training of physical education teachers}

This article collects works accumulated by the author in the first decade of the 21st century, a time dedicated especially to studies about professional training in Physical Education. It deals with the university entrance process and the relationship between the people involved in that institution with the professional training process. In the pedagogical practice inherent to this relationship, it makes considerations about the inseparable aspects that permeate the process of teaching and learning, questions the way knowledge is treated in undergraduate courses and the consequences of such treatment in professional activities. It defends a single, general teacher training, centered on educating human beings.

Keywords: University. Professional training. Physical education. Wide-scoped teacher training.

\section{Universidad: espacio privilegiado para la formación de profesores de educación física}

Este trabajo reúne una acumulación de trabajos del autor en la primera década de este siglo, especialmente el tiempo dedicado a los estudios sobre la formación profesional en Educación Física. Describe el proceso de ingreso a la universidad y la relación de los actores de esta institución con el proceso de formación. En la práctica pedagógica inherente a esa relacioón, realiza consideraciones sobre la unidad que del proceso de enseñar y aprender, cuestiona el tratamiento del conocimiento que ocurre en los cursos de graduación y las consecuencias que esta realidad provoca en los espacios de intervención profesional del área. Apoya la formación única y general para la licenciatura ampliada centralizada en el desarrollo humano.

Palabras clave: Universidad. Formación de profesores. Educación física. Licenciatura ampliada. 


\section{De onde e do que falo}

A relação que articula a universidade e a sociedade é que tem garantido um reconhecimento público à prática social desta instituição, pela legitimidade que ela, suas atribuições e ações devem ter, fundadas no princípio da diversidade. Tal contexto, que é histórico, aponta necessidades que the são inseparáveis, concedendo uma autonomia privilegiada perante outras formas institucionais, por estar estruturada com ordenamentos, regras, normas e valores cujo reconhecimento e legitimidade se dão "em seu próprio âmago", o que a torna uma instituição pública (Chauí, 2003).

Nestes tempos, a universidade tem pendido mais para empresa que instituição de ensino, o que afasta suas possibilidades históricas e reforça metas de uma sociedade capitalista na divisão e na exclusão sociais (Chauí, 2003). As reformas do Estado brasileiro vêm transformando os bens sociais e públicos (como saúde e educação) em prestação de serviços. No caso da educação, a constante transferência do ensino superior ao setor privado e as políticas públicas para o setor dão sentido ao ensino, pela certificação.

Nesse contexto, ocorre um encadeamento da universidade de instituição para organização, perdendo o seu caráter universal e ganhando uma particularidade histórica (Chauí, 2003). Na contramão, a educação não deve ser um bem de consumo, privilégio de alguns, mas um direito e obrigação de todos, portanto, direito e obrigação social, uma ação que se enverede pela qualidade social, o que implica um processo de formação humana.

Com orientações neoliberalistas, homens e mulheres perdem na relação de valores, pois a educação se torna mercadoria, inversão que exclui o sujeito pela alienação (Brzezinski, 2005). A autora faz uma crítica sobre a inserção do programa neoliberal da qualidade total na educação, cujos conceitos colocam que "qualidade na graduação" abarca cinco categorias inerentes ao processo acadêmico: ensino, pesquisa, extensão, práticas culturais e democratização da gestão.

A discussão da qualidade no âmbito educacional surge na década de 1980 e ganha ressonância nos diversos discursos a partir do surgimento do termo "qualidade de vida". Nas décadas seguintes, surgem as denúncias dos intelectuais que investiram criticamente contra o balizamento do processo pelos resultados na produtividade, na efetividade e na eficiência, defendidos pela sociedade mercantil ocidental, em prejuízo das condições de vida da humanidade e do meio ambiente. Freitas (2005, p.911) utiliza o termo "qualidade negociada" como uma proposta de contrarregulação: "Por este conceito, a qualidade é produto de um processo de avaliação institucional construído coletivamente, tendo como referência o projeto político-pedagógico da escola".

Conforme Juliatto (2006), de cada 100 alunos que entram no ensino fundamental, 45 chegam ao Ensino Médio e 20 o concluem. Segundo o autor, em outros países como 
Uruguai, Chile, Argentina e Coréia do Sul, o acesso ao ensino médio dá-se em torno de $20 \%, 30 \%, 40 \%$ e $80 \%$, respectivamente. Segundo Craveiro (2008), dos alunos que concluem o ensino médio, $9 \%$ chegam à Universidade e $6 \%$ a concluem, ou seja, no Brasil, a cada 100 alunos que entram no ensino fundamental, pouco mais que um torna-se graduado em alguma área do conhecimento.

Dentre essas áreas, temos a formação docente, que apenas na primeira década deste século passou a vigorar sob exigência de que o professor do ensino básico fosse licenciado pelo ensino superior. Guardam-se expectativas de qualificação para este contexto a partir de dados preocupantes do Brasil, onde a repetência no $1^{\circ}$ ano do ensino fundamental chega a $32 \%$, enquanto que no Paraguai e na Indonésia os índices chegam a $14 \%$ e $11 \%$, respectivamente (Craveiro, 2008). Segundo a autora, esse desajuste estaria ligado ao fato de que $56 \%$ dos alunos do ensino fundamental têm pais analfabetos. Penso que a formação de professores também tenha a ver com este cenário.

Dados das políticas públicas merecem considerações, como o fato das licenciaturas poderem ser integralizadas em 3 anos com carga horária de 2.700 horas, limites mínimos acatados na quase totalidade dos cursos em instituições privadas, acarretando um aligeiramento na formação de professores. Na formação profissional em Educação Física, no Estado de Goiás isso está materializado pelas IES particulares.

Por outro lado, a demanda por um espaço na universidade pode ser expressa pela sequente abertura de novos cursos neste Estado, especialmente na Capital Goiânia, em que o processo seletivo em 2008/1, assim se mostrou em três universidades:

- Na Universidade Estadual de Goiás, 29.1 candidatos por vaga, 30 vagas por turma;

- Na Universidade Federal de Goiás, 8.53 candidatos por vaga, 40 vagas por turma;

- Na Pontifícia Universidade Católica de Goiás, 2.98 candidatos por vaga, 60 por turma;

- Nas demais IES, todas privadas, não há retenção no vestibular, tendo em conta a relação candidatos/oferta de vagas (Fonte: comissões de seleção, sites das universidades).

Penso que os retidos no vestibular das instituições públicas sejam os filhos da classe trabalhadora que, não podendo pagar os valores cobrados pelas instituições particulares nem se aventuram aos processos de seleção dessas IES. Também por essas questões, a universidade segue considerada como um espaço de excelência, e deve ser esta a principal razão que motiva os indivíduos a buscar, mesmo em situações adversas, a sua entrada neste locus. Sem falar de exceções, segundo Juliatto (2006), cabe questionar: a universidade brasileira está mais próxima da excelência ou da mediocridade?

Há um alinhamento nesse projeto excludente, que se apresenta coerente com seus princípios, ao ladear educação e processo produtivo no desenvolvimento de uma pedagogia que estabelece intencionalmente as competências e habilidades que the interessam ver na classe trabalhadora (Brzezinski, 2007). 


\section{Pensando e dialogando com a prática pedagógica na formação de professores de Educação Física}

Embora na classificação do MEC a Educação Física esteja situada como subárea na grande área das Ciências da Saúde, desde a década de 1980 ela vem recebendo inserções das Ciências Humanas, especialmente da Educação, de forma relevante. Os novos conhecimentos emergem fazendo oposição àqueles que historicamente vinham dando a identidade à área (Ciências Biológicas).

Esta ampliação do corpo de conhecimentos se deu em um momento histórico da política nacional, mais ao final da ditadura militar que governou este país por duas décadas, a partir de 1964. Ao consolidar acordos bilaterais com os EUA, o governo ditatorial, por interesses tecnológicos no campo militar, consolidou também forte influência do paradigma tecnicista americano em áreas como a educação e a saúde; umbilicalmente ligada a ambas as áreas, a Educação Física promoveu um enlace propício entre a vertente tecnicista e o processo de esportivização, que ganhou muito apoio por parte dos militares brasileiros, consolidando uma abordagem que se institucionalizou tanto na escola como nos demais espaços de intervenção profissional da área, promovendo uma sedimentação técnica, biológica e esportivizada no campo, tendência que se tornou predominante.

$\mathrm{Na}$ área educacional, o acordo (MEC-USAID) ${ }^{1}$ concretizou a vinda de técnicos americanos para o Brasil a fim de ministrar cursos de especialização, tanto em nível de extensão como em lato sensu, bem como uma assessoria técnica ao sistema educacional brasileiro. Outra ação que se deu foi o deslocamento de professores brasileiros vinculados a cursos superiores para os EUA, que receberam bolsas para formação continuada em nível stricto sensu em universidades americanas. No caso da Educação Física, os cursos das universidades americanas disponibilizadas (San Diego e Wiscounsin) tinham eixo centrado no tecnicismo (Moreira, 1995; Betti, 1991).

Com a reabertura política na década de 1980 e o fim do acordo com os americanos, restou aos professores de Educação Física uma dura realidade, sem bolsa para o processo externo de titulação, apenas um programa de mestrado e nenhum de doutorado na área. 0 caminho foi buscar nos programas em Educação, principalmente, mas também em outras áreas das Ciências Humanas e Sociais e nos programas em Ciências da Saúde, a formação continuada stricto sensu. Esta realidade ainda se mantém hoje nas regiões Centro-Oeste lque conta com 01 doutorado em universidade privada e

1. Agência americana criada para "colaborar" com o desenvolvimento de países latino-americanos. Com isso, durante a Ditadura Militar, estudos, relatórios e planos da organização da educação formal brasileira foram desenvolvidos por especialistas americanos, prevalecendo um controle técnico (Ver Moreira, 1995). 
02 mestrados, um privado e um público), Nordeste (com um mestrado público) e Norte (sem nenhum programa stricto sensu), regiões onde os professores com graduação em Educação Física se fazem mestres e doutores em áreas correlatas².

Neste contexto, ainda que a maior parte das dissertações e teses tenha como objeto de investigação temas extraídos de problemas da especificidade da Educação Física, inevitavelmente, a produção do conhecimento estabelece diálogo com a literatura crítica das Ciências Humanas e Sociais apropriando-se desses saberes, pouco explorados até então pela área, tendo como conseqüência um movimento no pensamento da Educação Física, chamado inicialmente de "ebulição do campo" (Ghiraldelli Jr., 1991).

Estes novos conhecimentos causaram uma polarização até então jamais vivida pela Educação Física, alavancando conflitos que a levaram a uma instabilidade epistemológica e à perda de sua identidade (Bracht, 1999a). É bom lembrar que a Educação Física, em sua particularidade histórica, tem um processo de constituição do conhecimento unilateral, com o domínio de um paradigma que em nenhum momento anterior teve oposição que o molestasse:

A chamada Educação Física moderna é filha da modernidade. Isso significa que ela surge num quadro social em que a racionalidade científica se afirma como a forma correta de ler a realidade, em que o Estado burguês se afirma como forma legítima de organização do poder e a economia capitalista baseada na indústria emerge e se consolida. A Educação Física moderna sofre a influência, desde seus primeiros passos, do pensamento científico (Bracht: 1999a, p.28).

Este "científico" pertence à Ciência Moderna que na Educação Física se apresenta mais pelas Ciências Biológicas desde o nascedouro, mais especificamente pela Anatomia e a Fisiologia. Com a oposição de outros conhecimentos, o campo entra em "crise de identidade", entendida pela falta de definição de seu objeto (Bracht, 1999a). Para o autor, - objeto da Educação Física estaria no saber que orienta sua prática pedagógica: "Não estou me referindo, portanto, ao objeto de uma prática científica específica" (Bracht, 1999a, p.41). Entendo, então, que não se exigiria, nesta perspectiva, as mesmas explicações epistemológicas para se definir o objeto, como se a Educação Física fosse uma ciência. Bracht (1999a, p.42) segue na defesa de seus pressupostos: "Essa diferenciação é importante porque entendo que parte das dificuldades de superação da 'crise de identidade' advém do fato de se insistir em ver na Educação Física uma disciplina científica e, mais, uma disciplina com estatuto epistemológico próprio".

2. Ao todo são 21 programas no nível de stricto sensu, ficando o sul e o sudeste com 18 deles instalados em universidades destas regiões, consolidando uma profunda concentração e, em consequência, uma miserável exclusão das regiões com maior necessidade de mestres e doutores. 
Neste cenário, há de se considerar a produção do conhecimento no âmbito do stricto sensu como indicador teórico para a disputa da hegemonia no pensamento do campo da Educação Física. Temos então um paradigma (hegemônico) cuja produção do conhecimento se sustenta em maior incidência sobre objetos das ciências que discutem a saúde, coerente com o processo histórico da área, prevalecendo o pensamento sustentado pela Lógica Formal.

Outro paradigma (emergente e contra-hegemônico), não nega a importância e a necessidade para o campo da Educação Física dos conhecimentos científicos inerentes à saúde humana, mas entende fundamentais os conhecimentos produzidos no âmbito das Ciências Humanas e Sociais para o papel das práticas corporais, no contexto das relações sociais. Este pensamento se sustenta pela Lógica Dialética, com centralidade na formação humana por ter como seu objeto o Ser Humano (Ventura, 2010).

Neste contexto, enquanto uma prática educativa, a Educação Física precisa dar conta de se elaborar teoricamente. Penso que, com a compreensão mais ampla dada para o campo pelos conhecimentos das Ciências Humanas e Sociais, o quadro epistemológico da Educação Física ganhou qualidade e densidade, possibilitando um acúmulo teórico/ metodológico que poderá melhorar sua prática pedagógica e social.

Nos espaços da intervenção profissional, a prática pedagógica da Educação Física segue dois vieses:

- Um, predominante, cuja intervenção se dá por uma prática pela prática, um fazer corporal que não explica o seu saber, se desenvolve pela aparência do objeto;

- Outro que tem como objeto a formação humana; nele, as práticas corporais são contextualizadas com as relações sociais dos indivíduos participantes, pelas quais se articula o fazer corporal pelo saber que o orienta.

A segunda prática loponente da primeiral sempre esteve presente no processo da intervenção profissional da Educação Física, nos seus diversos espaços, independente da ciência que the era fonte dos conhecimentos. Nas duas últimas duas décadas do século XX e neste século é que esta prática conta com uma ancoragem teórica produzida pelos pressupostos das Ciências Humanas e Sociais.

Os estudos de Bracht (1999a; 1999b), Castellani Filho (1991; 1998) e Ventura (2010), considerados na relação com as intervenções pedagógicas nos cursos de formação em Educação Física e nos diversos espaços de atuação profissional, indicam que as abordagens mais presentes no campo do conhecimento da Educação Física têm como fonte orientadora o Paradigma Positivista. Ao emergirem abordagens teórico-metodológicas como a Crítico-Superadora (Coletivo de Autores, 1992) e Crítico-Emancipatória (Kunz, 2000), com aporte no Paradigma Dialético, se reforça a prática contra-hegemônica nas suas elaborações teóricas, possibilitando intervenções transformadoras para a Educação Física. 
Nas práticas corporais predominantes, os temas sobre o Esporte e a Ginástica prevalecem entre os conteúdos abordados. Na abordagem esportiva são as características competitivas inculcadas pela mídia, na lógica posta pelo modo de produção vigente; a ginástica se destaca pelo fitness e pela musculação, modismos que se espalharam pelo mesmo processo, sob roupagens que fazem da velocidade sua cientificidade, ou seja, a cada congresso uma novidade. Assim, ganham a preferência na "aprendizagem" de alunos e alunas em cursos de graduação, na extensão e na especialização, instituindo uma representação da Educação Física. Esse formato vem muitas vezes na esteira dos objetivos das políticas sobre a saúde, inculcadas por uma responsabilidade individual, alinhada como "promoção da saúde". .

Pensar a Educação Física na relação com a Educação, esta entendida como um fenômeno objetivo cuja prática é social e tem aporte científico na Pedagogia (Libâneo, 2007), constitui um processo educacional (de formação humana) articulado a várias modalidades educacionais, entre as quais a Educação Física, que corrobora com este movimento por uma prática educativa cuja essência é a prática corporal - uma necessidade universal humana - com sentido e significado próprio, ainda que não tenha objeto de estudo que consagre os critérios postos pela Ciência Moderna lobjeto próprio e exclusivo).

Na análise do que cerca predominantemente a prática pedagógica da Educação Física por uma "lógica mecanicista", seu objeto de estudo se materializa numa "Corpolatria" (González e Fensterseifer, 2005), um neologismo que atribui um culto ao corpo, alienação típica da "classe média" (trabalhadora) da sociedade capitalista, especialmente acentuada pelo mundo globalizado. Nesta lógica de pensar a Educação Física, o objeto de estudo tem olhar para um corpo dicotomizado, que objetifica o sujeito, numa perspectiva externa cujos artifícios neutralizam sua consciência, pela sua fragmentação na relação com o corpo.

A oposição paradigmática que emerge na década de 1980 e se consolida na seguinte com aporte no pensamento dialético tem como um dos marcos a publicação da obra Metodologia do Ensino de Educação Física (Coletivo de Autores, 1992), que propôs uma abordagem ancorada no Materialismo Histórico Dialético e na Teoria Educacional Histórico-Crítica, conhecida como Vertente Crítico-Superadora, que reconhece no conhecimento o mediador da relação professor e aluno, portanto entre ensino e aprendizagem, não abrindo mão de uma "diretividade pedagógica” (Castellani Filho, 1998).

Seus pressupostos defendem uma intervenção do professor ou professora que trabalhe intencionalmente com conhecimentos que possam suprir as necessidades sociais de estudantes filhos e filhas do proletariado. Apesar da escola lem todos os níveis de ensino) ser, sabidamente, um instrumento reprodutor do modo de produção capitalista 
(Snyders, 1981; Mészáros, 2005; Saviani, 2008; Ventura, 2009), é preciso levar em conta que, "contudo, há tarefas pedagógicas que são possíveis e necessárias na sociedade atual: não aguardaremos o dia imediato à revolução para tirar da escola o máximo que ela possa dar" (Snyders, 1981, p.394).

Esta diretividade implica que, se o professor deseja se opor à sociedade dominante na organização do trabalho pedagógico, deve estabelecer estratégias de ensino para que os conhecimentos que têm sido privilégio desta classe cheguem à classe trabalhadora. Isso remete pensar um processo educativo que considere a história das lutas de classe, como pensado por Marx e Engels no interior da sociedade capitalista, onde as classes fundamentais se diferenciam mais claramente (Bottomore, 1988). A consciência de classe social apreendida no Materialismo Histórico Dialético funda outras categorias de análise aqui empregadas ${ }^{3}$.

Na perspectiva da Vertente Crítico Superadora, a Educação Física se apresenta como uma disciplina pedagógica cujo objeto de estudo é a Cultura Corporal, que se apropria de temas oriundos do Conhecimento Popular la Ginástica, a Dança, a Luta, o Jogo, o Esporte, dentre outros) dando-lhes um tratamento pedagógico e científico, a partir dos postulados das teorias que integram as Ciências da Saúde e as Ciências Humanas e Sociais. Isso, para constituir seu campo epistemológico e desempenhar seu papel social que é, a meu ver, a "formação humana" dos indivíduos, para que eles possam compreender suas possibilidades nos campos da educação, da saúde, do lazer, do trabalho, bem como nas relações sociais com outros indivíduos.

Importante esclarecer que todo indivíduo tem inerente a si uma cultura corporal, porque, se humanos temos um corpo e uma cultura sobre ele. No entanto, a Educação Física na perspectiva da Vertente Crítico-Superadora não aborda toda esta dimensão corporal, ou seja, não investiga todas as práticas corporais ou todos os movimentos humanos, mas aqueles que the dão significado e sentido, enquanto uma Teoria Pedagógica.

Para Taffarel (2003, p.2),

A Cultura Corporal é entendida e configurada como um acervo de conhecimentos socialmente constituídos e historicamente determinados, a partir de práticas corporais que mantenham as relações múltiplas entre as experiências lideológicas, políticas, filosóficas, sociais), os sentidos (lúdicos, estéticos, agonistas, artísticos, competitivos e outros relacionados à realidade), às necessidades e às motivações do ser humano. (Taffarel, 2003, p. 2)

3. Outras categorias usadas foram alienação, totalidade, ontologia, dialética (materialista), fetiche, dentre outras, que não ganharam maior explicitação pela obediência aos critérios de espaço. 
Outra abordagem que tem sido bastante pesquisada, orientando diversos trabalhos acadêmicos, tanto na graduação quanto na pós-graduação, é a Crítico-Emancipatória, que tem forte influência da pedagogia freireana e tece análises sobre o movimento humano, percebendo-se nela também pressupostos do francês Merleau-Ponty e do alemão Trebels (Bracht, 1999a). Sua proposta teórica defende uma concepção dialógica de movimento, uma forma de comunicação com o mundo (Kunz, 2000). Seus pressupostos dariam aos indivíduos uma possibilidade crítica e uma autonomia social que remontam aos pressupostos da Escola de Frankfurt. 0 objeto de estudo desta vertente está configurado na "Cultura de Movimento". Destaque-se por González e Fensterseifer (2005, p. 112) que "Pertencem à cultura de movimento todas aquelas atividades que envolvem o movimentar-se humano com características lúdicas, de jogo, de brincadeira, de ginástica, de apresentação e competição, reconhecidas num determinado contexto sócio-cultural".

No entanto, não se percebem claramente contemplados os movimentos sociais e os problemas sociais mais aguçados, próprios da particularidade do sistema hegemônico, e pertinentes às relações sociais de trabalho. Outra questão a ser registrada é que a proposta tem uma abordagem centrada no esporte, dentre os temas inerentes às práticas corporais humanas. Embora o autor trate também dos outros temas, faz uma abordagem bem ampla do esporte, se diferenciando de outros estudiosos sobre o tema, que o restringem ao espaço de competição. É possível destacar três manifestações pedagógicas nas encenações de ensino do esporte: "no plano do trabalho, da interação e da linguagem" (Kunz, 2000, p.69).

0 autor, no diálogo com a literatura pela qual referencia suas afirmações no campo teórico e metodológico, ao conceituar o objeto de estudo que orienta a Abordagem Crítico-Emancipatória da Educação Física pressupõe que todas as atividades do movimento humano ancoradas no esporte "[...] e que pertencem ao mundo do movimentarse humano, o que o homem [sic] por esse meio produz ou cria, de acordo com sua conduta, seu comportamento, e mesmo as resistências que se oferecem a essas condutas e ações podem ser definidas como 'cultura de movimento'" (Kunz, 2000, p. 68).

Há no contexto do campo outros estudiosos que se estruturam por aportes críticos e dialéticos e que fazem aproximações a esta proposta de Kunz (2000), mas defendem como objeto de estudo da Educação Física a "Cultura Corporal de Movimento”, induzindo ao pensar uma articulação entre os objetos das vertentes críticas aqui apresentadas e os termos cultura corporal (cuja fonte é alemã, com inspiração na tradição marxista e nos frankfurtianos) e cultura de movimento.

A constituição do processo educativo deve ter por princípio a ética, alicerce da educação, a qual ocorre em diversos espaços datados e determinados. Um deles, central neste trabalho - a universidade -,constitui um movimento social na história da civilização 
humana e está nomeada pela sociedade capitalista como a principal referência educacional. Tem-se nesta sociedade vigente que a ética é propriedade apenas dos seres humanos, com indicativo de ser o locus seguro para assentar as coisas corretas (Ventura et al, 2006). A modernidade estabeleceu a razão como eixo maior para a ética, determinando que a ética profissional seja a busca de uma prática social correta. Ocorre que ética e conhecimento científico se apresentam em pólos opostos, encaminhando que "A Educação Física ao privilegiar a objetividade científica não encontra espaço na ética, reduzindo-se a cumprir decálogos" (González; Fensterseifer, 2005, p. 113). Os autores estão a falar da Educação Física hegemônica, aquela que, desde o início de sua particularidade histórica, se constitui pelo e com o capitalismo.

A escola capitalista está determinada para se desenvolver pelo ocultamento dos conhecimentos; para tanto deve fazer uso da metodologia empírico-analítica, pela qual a forma (o comol é prioritária, se não única. Isso por si só definha o ensino e marginaliza a aprendizagem. Na perspectiva de uma educação para além ou apesar do capital, o que ensinar e o porquê ensinar certamente tornariam a forma num apêndice do processo, pois o método utilizado seria outro, o dialético.

A educação no Brasil está longe do que possa querer a classe trabalhadora, o que temos são desafios educacionais numa sociedade de classes. Para Saviani (2008, p.267), “A situação brasileira, no entanto, apresenta desafios específicos que se ligam ao atraso em que se encontra a educação pública em nosso país relativamente ao próprio desenvolvimento da educação nas condições postas pela sociedade capitalista".

\section{Para além do mais, existem ainda outras considerações que podem...}

No contexto da educação superior é preciso pensar a relação da formação profissional com o projeto pedagógico e com o projeto curricular, o que torna necessário questionar: para quem devem ser focadas as indissociabilidades? Certamente elas não devem apontar os holofotes para as instituições, sua gestão acadêmica e seus professores, mas, a mira deve ser para o aluno, para o processo de ensino/aprendizagem, ou seja, pensar a relação ensino/pesquisa/extensão, pensar a relação teoria/prática e pensar a relação interdisciplinar para que a aprendizagem do aluno seja a mais qualificada possível. Entretanto, os resultados das pesquisas realizadas na formação em Educação Física, não apontam para esses procedimentos pedagógicos.

No ensino superior tem-se colocado em prática uma lógica de conceituar o professor pelo foco do conteúdo que ele domina, quer dizer, "o que e o quanto ele domina". Esses parâmetros não são suficientes, porque a todo instante faz-se necessário desvelar 
dúvidas, o que centra a importância da pesquisa e novos acúmulos do conhecimento. Considero o curso de graduação como espaço para a formação de raízes, onde os docentes não têm como concorrer com o estoque de informações que é passado diariamente pelas inúmeras formas tecnológicas da comunicação globalizada. Mas, um professor pode ampliar, aprofundar e contextualizar criticamente a discussão sobre temas, problemas e informes, incluindo uma seleção dos conhecimentos a ser tratados e os procedimentos de ensino a ser usados, ambos obedecendo uma diretividade pedagógica que the garanta seguir no encalço dos objetivos de seu planejamento, das "raízes que ele quer fincar".

Na universidade há de se ter a exigência de um conteúdo que passe por critérios críticos, com o aluno sendo orientado para buscar fontes que complementem o trato com o conhecimento desenvolvido em sala de aula, ou seja, fazer estudos paralelos, que acrescentem àquilo ensinado pelo professor. Isso significa estudar os textos, não somente lê-los, desenvolver uma sistematização sobre o conhecimento ensinado para ganhar qualidade na coesão e coerência de suas escritas, fazendo uma relação dialética entre o aporte teórico apreendido e o acúmulo do percurso de sua formação humana, da sua caminhada de vida. Antes, bastava que o aluno soubesse o "produto" da ciência; agora, ele precisa apreender o "processo" dos saberes científicos (Chauí, 2003). Para o Coletivo de Autores (1992), cabe um movimento indispensável: constatar o conhecimento, refletir sobre ele, compreendê-lo e ser capaz de explicá-lo.

A relação entre professor/professora, aluno/aluna e conhecimento demonstra com muita clareza a distância do projeto institucional e sua proposta pedagógica. Muitos docentes poderão dizer que trabalham com o currículo oculto, mas na verdade há uma completa omissão por parte dos atores da sala de aula e da gestão acadêmico/pedagógica na aproximação com as propostas formalizadas. Neste contexto, inclui-se a total desarticulação no processo de interdepartamentalização no interior das instituições universitárias, onde o dar aulas em outros cursos significa apenas cumprir carga horária. A Educação Física tem sido seriamente comprometida com esta realidade, pela absoluta falta de contextualização entre os saberes das disciplinas operadas por outros departamentos e sua prática social e pedagógica.

Sendo a universidade um locus educacional, ela deve articular a tríade conhecimento, aluno e professor. 0 conhecimento é central e medeia a relação aluno e professor, que se articula em função do conhecimento, em que o aluno deve ser o centro do ensino (compreendido o ensino como meio), e objeto da aprendizagem (como fim). Sem aluno, a universidade não resiste; articulados, conhecimento, aluno e professor garantem a finalidade da educação, a formação humana e o papel social da universidade.

Outra questão pertinente é que o acadêmico frequenta mais a copiadora que a biblioteca. Penso que o uso de textos torna-se um agravante quando simplesmente é recortado 
de obra, tese, revista, artigo, etc. fragmentando a reflexão sobre o ideário de seu autor ou autora e comprometendo uma compreensão mais ampla. Ao pensar uma articulação ensino/pesquisa, o professor deve buscar a produção dos conhecimentos que ensina, ou seja, elaborar e sistematizar processualmente saberes que contemplem seus objetivos, com a necessária re/elaboração diante daquilo que o docente aprende ao ensinar e ao pesquisar, o que ajusta o conceito de docência de que falo. Assim, ele avança para além de suas referências bibliográficas, pois estará contextualizando-as e re/significando-as, dando propriedade aos conhecimentos que mais se articulem ao contexto de seus alunos.

Quero ainda considerar mais uma questão, muito presente hoje na relação que envolve o processo de ensino/aprendizagem na graduação, que é a disponibilidade discente de tempo, na verdade, a prioridade ao tempo. Trata-se de um argumento de "primeira classe" que, somado ao velho discurso do acúmulo de conteúdos e trabalhos das outras disciplinas, colide com os objetivos docentes de alargar a cultura de estudos na graduação em Educação Física, especialmente na apreensão de complementaridades, o que deve ocorrer para além da sala de aula. 0 argumento perderá ressonância se os professores se articularem no planejamento coletivo das disciplinas, discutindo e projetando a complexidade e a intensidade dos trabalhos acadêmicos e usando a sala de aula como laboratório para orientar a elaboração e o desenvolvimento das ações discentes, o que garantirá um ritmo constante para os estudos. É o que se tem chamado de interdisciplinaridade.

A formação profissional em Educação Física, num recorte bem contemporâneo, pode ser apresentada em quatro fases. Até o final da década de 1960, e, especialmente no período da ditadura militar, ela era feita por licenciatura, e dava ao egresso dupla habilitação: a de professor de Educação Física e a de Técnico Esportivo. A licenciatura permitia trabalhar em todos os campos, e a função de técnico com equipes que participavam de competições, sendo automática a habilitação nos esportes que fossem oferecidos pela grade curricular de cada curso. Esta condição levou os diversos currículos a oferecer várias opções de disciplinas esportivas, as mais conhecidas ocorrendo em mais de um nível, muitas delas nos três anos de duração do curso, tempo mínimo normalizado pelo Ministério da Educação no citado período (Pereira Filho, 2005; Ventura, 2005).

As habilitações eram concomitantes e ocorriam assim em todo o país, tendo em vista que prevalecia a lógica de currículo mínimo, estratégia de política curricular que prevaleceu durante muitos anos, até porque era uma das condições para reconhecimento dos cursos. Neste período, o currículo mínimo para a formação em Educação Física delimitava e enfatizava duas fontes de conhecimento, a biológica e a pedagógica, ambas sob um forte aparato tecnicista. 0 Governo Militar, ao tomar o poder em 1964, encontrou no contexto da Educação uma legislação recém aprovada (LDB 4024/1961), 
mas com o decorrer do tempo foi reformulando a legislação e adaptando-a aos padrões determinados pelo autoritarismo.

Essas reformas tiveram início pelo Ensino Superior (Lei 5.540/1968) e, na Educação Física, pelo Parecer CFE-894/1969 e pela Resolução CFE-69/1969, que consolidaram a aprovação das primeiras diretrizes curriculares para a formação profissional na área. A reforma da educação formal, do ensino fundamental e médio foi realinhada pela Lei 5692/1971 na sua estrutura geral e o Decreto-Lei 69.450/1971 delimitou a Educação Física na sua especificidade. Adequava-se por esses atos legais o processo educativo às intransigências do modelo ditatorial (Pereira Filho, 2005; Ventura, 2005).

No campo da formação em Educação Física, as diretrizes exigiam uma carga horária mínima de 1.800 horas, integralizadas em pelo menos três anos (licenciatura plena), extinguindo a habilitação de técnico e inserindo a licenciatura curta (1 ano), prevalecendo a "aptidão física" como objeto orientador dos cursos, consolidando a prova prática do vestibular como habilidade fundamental para ser professor de Educação Física, o que exigia do acadêmico requintes de atleta. Pedagogicamente, era o aprender e o ensinar fazendo. 0 currículo mínimo manteve-se inalterado, determinando-se então que os professores de Educação Física seriam os profissionais indicados para desempenhar a função de técnico das equipes de competição, nas mais diversas modalidades esportivas institucionalizadas (Pereira Filho, 2005; Ventura, 2005).

Na década de 1980, começam a desmoronar os alicerces do governo autoritário, em função dos desgastes provocados pela insistente oposição do povo brasileiro, em especial da classe trabalhadora do ABC paulista e da classe estudantil do ensino médio e superior, bem como da pressão política internacional de entidades e sociedades de diversas partes do mundo. Nesse contexto, as escolas de Educação Física promoveram diversas reuniões para discutir a formação na área, ganhando em certo momento também o apoio do MEC, movimento que culminou com a aprovação, em 1987, pelo Conselho Federal de Educação - CFE, das diretrizes curriculares que se legalizaram pelo Parecer CFE 215/1987 e Resolução CFE 03/1987, constituindo as transformações mais significativas na história da formação em Educação Física no Brasil, para melhor e para pior (Pereira Filho, 2005; Ventura, 2005).

Assim, o tempo mínimo para a integralização foi aumentado de 3 para 4 anos; a carga horária mínima de 1.800 para 2.880 horas e a obrigatoriedade, algum tempo após, de 300 horas mínimas de estágio supervisionado. Embora com o discurso de romper com o currículo mínimo, esta resolução apenas o disfarçou, estabelecendo que os conhecimentos se agrupassem em eixos, e para cada um deles havia uma carga horária obrigatória mínima. Esta legislação acabou com a licenciatura curta, mas introduziu a duplicidade - licenciatura e bacharelado - que implantou a dicotomização na formação em Educação 
Física de maneira imprudente e determinante, contribuindo para a perda de identidade da área e encaminhando um processo que cada vez mais consolida duas possíveis profissões, duas áreas do conhecimento diferentes: uma que terá nas Ciências da Saúde seu carro-chefe e nos campos não escolares seu espaço de intervenção, e outra que comportará as teorias das Ciências Humanas e Sociais sem abrir mão dos conhecimentos biológicos, tornando-se o que denominamos hoje de campo do conhecimento "multidisciplinar", tendo como espaço de intervenção a escola (Ventura, 2005).

A atual política curricular para a formação em Educação Física tem início com as diretrizes curriculares para formação de professores em geral, as licenciaturas, aprovadas pelo Conselho Nacional de Educação via Parecer CNE/CP 09/2001, e pelas Resoluções CNE/CP 01 e 02/2002, complementando-se pelas diretrizes específicas da área aprovadas pelo Parecer CNE/CES 058/2004 e pela Resolução CNE/CP 07/2004, legislação essa que inspirou poucos avanços e alguns retrocessos. Como se nota, as diretrizes específicas só foram aprovadas mais de dois anos após a legislação sobre a formação de professores, tendo como causa o antagonismo entre pensamentos opostos. A dupla formação (licenciatura e bacharelado) inspirada a partir de determinações do mercado de trabalho trouxe desgaste para a área, especialmente com a intromissão do conselho profissional que impeliu proibições inconstitucionais aos trabalhadores da Educação Física.

As principais alterações das atuais DCNs da Educação Física foram o aumento da carga horária mínima do estágio supervisionado para 400 horas, recomendadas para ocorrer da metade do curso em diante; a inserção de 400 horas mínimas de prática de ensino recomendadas desde o início do curso; 200 horas de Atividades Acadêmicas Científico Culturais - AACCs para contemplar a flexibilização curricular, o aligeiramento da formação com a diminuição do tempo mínimo de 4 para 3 anos e da carga horária mínima de 2.880 para 2.800 horas. Do que foi mantido, destaque negativo para a manutenção da formação fragmentada em bacharelado e licenciatura, causa de um embate que já dura mais de uma década e se mostra distante de ser resolvido.

Este conjunto de determinações "legais" engessou docentes e discentes que teriam acesso apenas a conceitos aparentes, abstratos o suficiente para que os egressos dos cursos de Educação Física tenham uma prática pedagógica mecânica, de forma que suas intervenções fiquem no simples fazer corporal, desejo expresso da sociedade produtiva. Trata-se de um modelo de competências no qual o futuro professor deve assumir a responsabilidade individual pela sua formação, não considerando concepções críticas de que o trabalho pedagógico seja coletivo e político, nem percebendo que existe uma política global de formação profissional, cuja orientação é dada por fatores externos, como o Banco Mundial, o BIRD, o FMI, etc., que têm ditado as políticas públicas para os países em desenvolvimento. 
Desta forma, o conceito de competência é reduzido e simplista, fica propositalmente confuso entre o entendimento do que seja objetivo e princípio e se dá à função de justificar todo o processo de exclusão social nas relações de exploração humana. 0 aligeiramento na formação e o confisco de possibilidades críticas se desvelaram na simples equação de 2.800 horas ocupadas pelas práticas e disciplinas das Ciências Naturais; pensar, refletir, compreender e dar conta de explicar, não haverá tempo!

\section{Se a formação humana é contínua, as considerações seguirão seu processo...}

A formação profissional na área da Educação Física no Brasil, diferente das demais áreas sempre ocorreu pela licenciatura. 0 acúmulo histórico permite ao campo conceituar e requerer a formação "una" e, pela licenciatura, que tem como fonte a sua prática pedagógica, que também é histórica. Independente do espaço de intervenção profissional, a Educação Física se manifesta por uma prática educativa, que tem como essência a ação docente, o que implica uma relação social de ensino e aprendizagem.

Este pressuposto se materializou a partir da inclusão dos conhecimentos das Ciências Humanas e Sociais, que qualificam o acúmulo histórico feito pelas Ciências da Saúde e reforçam uma formação ampla e sólida que temos chamado de Licenciatura Ampliada.

As diretrizes atuais que orientam a formação em Educação Física foram aprovadas após muitos conflitos entre os pensadores do campo, na interlocução com o Conselho Nacional de Educação, o que gerou um avanço sobre um Parecer (CNE 0138/2002) aprovado e depois revogado. Mas, concretamente se perdeu um momento ímpar para fazer uso do acúmulo produzido sobre a formação e políticas públicas para a Educação Física nas duas últimas décadas.

Ao final do processo optou-se por um "acordo possível" que negou o processo histórico e impeliu a se pensar objetos diferentes para a licenciatura e o bacharelado. Como entender caminhos diferentes para a formação dupla que apontem a mesma indissociabilidade teoria/prática para uma e outra formação (nas AACCs, no Estágio, na Prática de Ensino), já orientadas anteriormente pelas diretrizes das licenciaturas? Só aparência, não se aponta para a essência que está sombreada no processo histórico, e isso ratifica o que alguns desvendamentos já aportaram: a separação só está pensada pela intervenção nos campos escolares e não-escolares e é protagonizada de fora, pelo movimento externo.

Essas e outras questões abordadas no corpo deste texto e, obviamente muitas outras que não fui capaz de articular, me convencem de que a formação em Educação Física deve 
se dar por base única, a “licenciatura ampliada”, que se pretende assim para possibilitar aos acadêmicos fazer os nexos e as mediações entre a parte e o todo.

0 conceito inspira lutar para que a Educação Física permaneça como um só campo de conhecimento. Então, uma única formação, já que na sua singularidade, a divisão do campo do conhecimento se dá unicamente pelos espaços de intervenção profissional, em que o bacharel, a partir da Resolução CNE/CES 01/2002 não pode intervir na Educação Física escolar. Bom esclarecer que não se trata de apologia ou ingenuidade inspirando que os paradigmas em oposição se tornem convergentes, até porque isso não remeteria sequer a um acordo possível. É que uma proposta dialética não pode deixar de levar em conta o postulado da unidade entre os contrários.

Se o conhecimento da Educação Física se deseja caracterizado por uma prática pedagógica, cujo objetivo seja a formação humana sustentada por um sólido acúmulo teórico/metodológico, esta conjunção qualitativa deverá ser orientada por sua produção científica, a qual irá ancorar o processo do ensino e da aprendizagem. Dois paradigmas que se oponham dentro de uma mesma área de conhecimento podem protagonizar um confronto saudável nesta direção; de outra forma, uma divisão da área com objetivo de evitar oposições, significa a rendição extrema que se possa chegar à perspectiva política e ideológica, o que não permitirá nada para além da reprodução.

Isto posto, cabe refletir sobre as costuras que se apresentam nesta emaranhada teia que abrange um curso de formação profissional, no interior de uma universidade. $\mathrm{Na}$ perspectiva do foco pedagógico, entendo que a discussão sobre a formação em Educação Física deva estar atenta a alguns questionamentos:

- O que se deve ensinar na Universidade? Nesse espaço de relações sociais de trabalho, onde se busca responder necessidades sobre o conhecimento humano para formas de sobrevivência, só se justifica se ensinar coisas difíceis, ainda abstratas para os alunos, já que em outros espaços eles não conseguiriam torná-las concretas em seu pensamento;

- Por que um determinado conhecimento e não outro? 0 contexto é uma das fontes que definem o que ensinar, conhecer a sociedade e o mundo onde se está inserido; concordar ou discordar desta realidade é uma questão que fundamenta a autenticidade do conteúdo de ensino selecionado;

- Para que ensinar? Para manter ou para transformar a sociedade em que estamos inseridos. Este caminho exige uma leitura da questão anterior, cujo entendimento crítico ou não, vai ser fundamental e implicará uma tomada de posição política;

- Para quem ensinar? Articulada à $1^{\text {a }}$ questão deve-se ensinar para a classe trabaIhadora o conhecimento da classe hegemônica, para compreender o engendramento do sistema vigente e as estratégias de exploração;

- Como tratar o conhecimento? Como ensinar? É preciso, diante da realidade posta, definir que método utilizar, portanto, situar de "onde" se vai falar, qual teoria susten- 
tará o trabalho pedagógico; como parte do processo, as estratégias metodológicas também precisam ser pensadas;

- Onde tratar o conhecimento revolucionário? Na sala de aula, na biblioteca, nos espaços de trabalho e outras tantas possibilidades no interior das relações sociais que envolvam a classe trabalhadora.

Como considerações temporariamente derradeiras e para dar suporte às questões sobre a formação profissional em Educação Física, defendo que um acadêmico deva dominar as matrizes do conhecimento com a densidade necessária para fazer a opção por uma delas e, por consequência, definir a vertente teórica da Educação Física que dará aporte à sua prática profissional. Para além disso, também vejo da maior importância que ao terminar a graduação ele tenha bom domínio de, pelo menos, dois campos de intervenção, um deles necessariamente a escola, tendo em vista as pesquisas apontarem que muitos egressos que não tiveram interesse por essa discussão mas acabam aterrisando na escola por questões de estabilidade, condições de trabalho, salário, assistência à saúde etc.

Defendo há algum tempo a tese de que a Educação Física escolar não vem sendo competente para ensinar os fundamentos científicos que dão sustentação à Educação Física como campo do conhecimento, o que nega aos indivíduos o conhecimento básico sobre as práticas corporais, por serem elas universais, então necessidades ontológicas dos sujeitos. Neste cenário, a continuidade durante toda a vida de exercitar-se é uma questão de conhecimento negada pela Educação Física no âmbito escolar.

Como decorrência, as pessoas vão à academia, por exemplo, por questões ligadas à saúde (doença) e encaminhadas pelo médico; ou então relacionadas à estética corporal - capitalista, claro - encaminhadas pelo fetiche desenvolvido pela mídia sustentada pelo modo de produção vigente. Esta "não-consciência" dos indivíduos sobre as práticas corporais escancara o "não-trabalho" pedagógico da Educação Física escolar.

A área lida com problemas em três momentos distintos no movimento de sua prática social: na produção do conhecimento, na formação e na intervenção profissional. Entre todas, vejo que uma delas, não abordada neste trabalho de forma direta, se constitui com maior responsabilidade no fomento aos percalços do campo do conhecimento e na produção, que se dá de forma mais densa e complexa pelos mestrandos e mestres, doutorandos e doutores. São eles que produzem o conhecimento da área com maior alcance de publicação, e com maior poder de influência nos cursos de formação (graduação) e nos espaços de trabalho dos professores e professoras de Educação Física.

Assim, como parte integrante da universidade e como processo de formação, a pósgraduação pode ser contextualizada para muitas das discussões feitas aqui, sobre formação humana e profissional. Pela espiralação dialética dar-se-ia conta de uma 
formação acadêmica ampla e sólida teoricamente, para encaminhar a intervenção profissional a favor de uma prática pedagógica com qualidade suficiente para promover a formação numa perspectiva crítica que possibilite pensar sobre a necessidade lou não) de uma transformação social.

Uma universidade cujo curso de licenciatura articule os postulados aqui tratados apontará para uma transformação, o que remete o processo de formação à materialização da práxis, como possibilidade para uma formação capaz de alavancar uma revolução social. Práxis aqui deve ser entendida na perspectiva de uma atividade humana, material, que na sua ação prática transforma a realidade e, por isso, transforma também o próprio ser humano.

Esta universidade que desenhei, nas relações sociais com o povo brasileiro deve se constituir como uma instituição que valorize seu papel histórico na produção da ciência e na consolidação da cultura nacional, com tendência e vontade política para realizar intervenções no contexto social, a fim de desobscurecer a realidade encoberta pelo sistema vigente. E, que a Educação Física faça parte deste contexto.

\section{Referências}

BAPTISTA, Tadeu João Ribeiro. Procurando o lado escuro da lua: implicações sociais da prática de atividades corporais realizadas por adultos em academias de ginástica de Goiânia. 2001. Dissertação (Mestrado em Educação). Goiânia: Faculdade de Educação da Universidade Federal de Goiás. 2001. BOTTOMORE, Tom. Dicionário do pensamento marxista. Rio de Janeiro: Jorge Zahar, 1988.

BETTI, Mauro. Educação Física e sociedade. São Paulo: Movimento, 1991.

BRACHT, Valter. Educação Física \& ciência: cenas de um casamento (in)feliz. ljuí: Unijuí, 1999a.

BRACHT, Valter. A constituição das teorias pedagógicas da Educação Física. Caderno Cedes. Campinas, UNICAMP, n. 48, p. 69-88, ago. 1999b.

BRZEZINSKI, Iria. Qualidade na Educação. EducAtiva, Goiânia, PUC-G0, v. 8, n. 2, p.321-338, jul./dez. 2005. . Educação contemporânea: questões sociais, econômicas, históricas, culturais e políticas. (mímeo). Goiânia: PUC-GO, 2007. (mímeo)

CASTELLANI FILHO, Lino. Educação Física no Brasil: a história que não se conta. 3. ed. Campinas: Papirus, 1991.

. Política educacional e Educação Física. Campinas: Autores Associados, 1998.

CBCE - GTT Formação Profissional e Mundo do Trabalho. Parecer sobre a proposta da COESP para as Diretrizes Curriculares da Educação Física. Vitória, 2003. (mímeo)

CHAUÍ, Marilena. A universidade pública sob nova perspectiva. Poços de Caldas: ANPED, 2003.

COLETIVO DE AUTORES. Metodologia do ensino de Educação Física. São Paulo: Cortez, 1992.

CRAVEIRO, Clélia Brandão Alvarenga. Planejamento Pedagógico do DEFD/PUC-GO (mímeo) Goiânia, 2008.

FREITAS, Luis Carlos de. Qualidade negociada: avaliação e contra regulação na escola pública. Educação \& Sociedade. Campinas, UNICAMP, v. 26, n. 92 (especial), p. 911-933, out. 2005. 
GONZÁLEZ, Fernando Jaime; FENSTERSEIFER, Paulo Evaldo. Dicionário crítico de Educação Física. ljuí: Unijuí, 2005.

GHIRALDELLI JÚNIOR, Paulo. Educação Física progressista: a pedagogia social dos conteúdos e a Educação Física brasileira. 3. ed. São Paulo: Loyola, 1991.

JULIATTO, Clemente Ivo. Planejamento Pedagógico da PUC-GO. Goiânia, 2006. (mímeo)

KUNZ, Elenor. Transformação didático-pedagógica do esporte. 3. ed. ljuí: Unijuí, 2000.

LIBÂNEO, José Carlos. Que são “questões” no campo investigativo da pedagogia? Goiânia: PUC-Go, 2007. (mímeo)

MÉSZÁROS, István. A educação para além do capital. São Paulo: Boitempo, 2005.

MOREIRA, Antonio Flávio Barbosa. Currículos e programas no Brasil. 2. ed. Campinas: Papirus, 1995.

PEREIRA FILHO, Ednaldo. Limites da formação e exercício profissional. In: FIGUEIREDO, Zenolia Christina Campos (Org.). Formação profissional em Educação Física e mundo do trabalho. Vitória: Salesiana, 2005. p. 47-69.

SAVIANI, Dermeval. Educação socialista, pedagogia histórico-crítica e os desafios da sociedade de classes. In: LOMBARDI, José Claudinei; SAVIANI, Dermeval (Org.). Marxismo e educação - debates contemporâneos. 2. ed. Campinas: Autores Associados, 2008. p. 223-274.

SNYDERS, Georges. Escola, classe e luta de classes. 2. ed. Lisboa: Moraes, 1981.

TAFFAREL, Celi Nelza Zulke. Relatório GTT Formação Profissional e Mundo do Trabalho. Campinas: CBCE, 2003. (mímeo)

PONTIFÍCIA UNIVERSIDADE CATÓLICA DE GOIÁS. Comissão do Processo Seletivo. Goiânia, 2008.

UNIVERSIDADE ESTADUAL DE GOIÁS. Comissão de Vestibular. Anápolis, 2008.

UNIVERSIDADE FEDERAL DE GOIÁS. Comissão do Processo Seletivo. Goiânia, 2008.

VENTURA, Paulo Roberto Veloso. Formação profissional em Educação Física: um desafio posto pelas diretrizes curriculares. Revista Estudos, Goiânia, PUC-G0, v. 32, n. 3, p. 353-385, mar. de 2005.

et al. Formação continuada em Educação Física na rede estadual pública de Goiás: um projeto extensionista que desafia a UEG e a SEE. Anais do XIV CONBRACE e I CONICE. Porto Alegre: CBCE, 2005. jan./jun. 2009.

Educação e ensino para além do capital. EducAtiva. Goiânia, PUC-GO, v. 12, n. 1. p. 125-136, VENTURA, Paulo Roberto Veloso. A Educação Física e sua constituição histórica: desvelando ocultamentos. 2010. Tese (Doutorado em Educação) Programa de Pós-graduação em Educação da PUC-GO, 2010.

Recebida $1^{\text {a }}$ versão em fevereiro de 2010

Aprovada $2^{\text {a }}$ versão em abril de 2011

Paulo Roberto Veloso Ventura, Doutor em Educação pela PUC-GO. Docente nos cursos de licenciatura em Educação Física na Universidade Estadual de Goiás e Pontifícia Universidade Católica de Goiás, tendo publicado “Educação e Ensino para além do Capital” (Revista: Educativa UCG, 2009); “A Interiorização da Formação Continuada: um desafio para a Educação Física” (Estudos UCGO, 2006). E-mail: paulo.pintadgmail.com 